\title{
A Philosophy of Design Course that uses Student Questions as the Basis for Discussion
}

\author{
M.G.(Ron) Britton \\ Associate Dean (Design Education) \\ J.M. (Mal) Symonds \\ Faculty of Engineering, University of Manitoba \\ ron britton@umanitoba.ca \\ mal_symonde@umanitoba.ca
}

\begin{abstract}
In the fall of 2003 a new interdepartmental graduate class that addresses design from a philosophical rather than a technical perspective was introduced. The class utilizes five different books to present varied views of both the processes and effects of design. Each book is considered in sequence. Three hour long class meetings are held every second week, over two terms.

From its inception, the course has been based on discussion rather than instruction. The format that informs the discussion has evolved with experience. The intent is to use opinions expressed in the books to encourage students to develop their own opinions regarding the Engineering profession in general, and design philosophy in particular.

The course has been offered to classes ranging from three to 20 students. In one case, it was offered using interactive video connections to three students at two different schools.

This paper discusses how the course is delivered and how that delivery has evolved due to student input.
\end{abstract}

\section{Introduction}

The introduction of NSERC programs in support of Chairs in Design Engineering and Environmental Design Engineering caused a renewed debate in academic circles regarding the definition of design. Typically this debate was most vigorous at institutions where Chairs were awarded.

At the University of Manitoba, the debate centered on the question of definition. Was design simply the application of scientific knowledge to questions defined by others, or was it a process by which solutions could be sought, regardless of the underlying science?

In the spring of 2003, based on these debates and a growing volume of design philosophy literature, the decision was taken to introduce an interdepartmental graduate class that addresses design from a philosophical rather than a technical perspective. The course has been offered on a annual basis since the fall of 2003.

\section{The Course Concept}

The ENG 7010 - The Engineering Design Process Course Philosophy is defined in the Course Outline that is provided to all students. While delivery details have changed since 2003, the Philosophy statement has remained consistent.

"The course will examine a multiplicity of perspectives on design in general and engineering design in particular. The concept of "process" will be addressed in a general rather than a specific manner. Given that engineering design produces unique solutions that are dependent on the input constraints, a course that deals with design should produce unique conclusions. Students will be encouraged to use the course material to develop their definitions of their personal design philosophies."

This is a three credit course, delivered in biweekly, three-hour meetings over two terms. Functionally the course is based on five different books that present varied views of both the processes and effects of design. Each book is considered in sequence. Classes are based on student input and discussion.

\section{Course Delivery}

The course is "delivered" by the authors, who serve as facilitators rather than lecturers. Given that students are drawn from all fields of engineering, it is often necessary to create broad based supplemental background material to put either texts or discussions in context. Handouts and current news clippings are distributed at least a week prior to the next class in order spread the work load for students. 
Procedurally we begin the course by requiring each student to submit a written "personal design philosophy". This assignment is transmitted to students as soon as they register for the course and is due before the second class meeting. Frequently students seek personal advice as they attempt to put design into a philosophical framework. Once submitted, the design statements are discussed with individuals, but not shared with others. This "early" requirement, and the subsequent discussions, help students understand what the course is about. While this causes a rush of communication, both face-to-face and e-mail, it enables students to make an informed decision regarding their continued participation. It also helps the instructors better understand the "mind set" of the incoming class.

The "personal design philosophy" assignment is repeated as the final requirement for the course. Again, discussions are held with individuals, if they wish.

The first class meeting is spent making students comfortable in a discussion driven environment. The course is offered in a classroom furnished with moveable tables and chairs. "Name plates" are provided and no one is permitted to sit in a position where they are looking at the back of someone's head. Everyone introduces themself and explains why they signed up for this class. Once class delivery formalities are finalized, each student is asked to identify the most important historic engineering contribution. Duplicate items are not permitted. The process follows the rules of Brainstorming where there is no such thing as a wrong answer. Typically the environment becomes increasingly relaxed, but those who are reluctant to speak are specifically called upon. This approach has two outcomes. Some students withdraw from the class once they realize what it involves. Many of those who remain begin to consider the historic context of the discussions that develop during later classes.

Readings are based on five books that are presented for consideration in the following sequence: Billy $\mathrm{V}$. Koen, Definition of the engineering method.[1], Samuel C. Florman, The existential pleasures of engineering.[2], Henry Petroski, Design paradigms.[3], Ursula M. Franklin, The real world of technology.[4], and James R. Chiles, Inviting disaster.[5]. These books provide a range of perspectives, from a tradition approach through, technical responsibility, learning from failure, social responsibility and social impacts. All books speak to the design process from different perspectives. None of the books include mathematical explanations. It is fair to say that, so far, none of our students had read any of these books prior to enrolling in the course.

When the course was first offered students wrote "book reports" on each of the books and briefly presented, and "defended", their reports in class. Each student had at least half an hour "on stage" and it typically took two classes to consider everyone's submission. Discussions tended to focus on the specifics of what each book's author said, usually without reference back to previous books or authors. Because the books were treated like texts, the tendency was to treat the material as "fact" rather than opinion. Printed copies of individual submissions were not shared before the class.

We changed from the "book report" approach part way through the 2005/2006 academic year, after reading an article written by Laura Greene[6\}, an English Professor at Augustana College. Based on suggestions in this article we asked our students to share questions that had occurred to them as a result of having read each book. The change in process was very well received. Interestingly, students seemed to be empowered to take a critical view of the material. We now use the "questions" approach exclusively.

Once the course is under way, each book requires a four week period of consideration. A specific book is assigned and students are expected to submit two questions that arose as a result of reading that specific book. The questions are submitted 48 hours prior to the next class. All questions are complied in a standard format and distributed, anonymously, 12 hours later. These questions provide the basis for in-class discussions. In order to initiate discussion during early class meetings, students are asked to explain to the class what caused them to ask one of their questions. Reactions to both the question and the explanation tend to provide the necessary stimulus. The instructors introduce current developments or historic events to broaden or focus the ensuing discussion as necessary. As the year progresses and students become more familiar with the format, discussion can often be initiated by simply asking who wants to start.

Two weeks after the "questions" session, each student must "respond" to two of the questions posed by others. Again written "responses" are due 48 hours before class, they are formatted and distributed for prior review by the students. Discussions in this class, while fueled by the written "responses" usually become much more wide ranging. Frequently previous in-class discussions are recalled, compared and contrasted with positions based on the current reading. The cycle then repeats itself with a new book over the following month.

\section{Course Administrivia}

All written communication is exchanged via e-mail. In order to facilitate formatting prior to material distribution, all student submissions must be imbedded in 
the body of the e-mail message. This "lowest common denominator" simplifies formatting, consolidation and return of the material in a timely manner.

All student submissions are reviewed and stored. Given that the "questions" and "responses" are based on individual student's opinion, we do not grade the submissions against an "acceptable standard" answer. We stress that there are no "correct" answers. Many students have trouble with this concept, they have, after all, attained their current status by providing "right" answers to questions. We require a "professional" standard in all communication.

Individual communication regarding the logic, clarity and grammatical standard in student submissions is offered both personally and electronically, which ever seems to be the most appropriate format for the specific situation. Given that the language of communication is English, and given an increasing enrollment of students for whom English is an alternate language fundamental grammar can be a problem. This can become time consuming.

The five books selected for the course are all available either in paperback or electronically. This was a conscious decision given the cost of textbooks.

Assessment is based on participation. At the beginning of the course each student is assigned an

"A". Inadequate participation, either oral or written, results in a warning and discussions around

the requirements to retain, or exceed, the initial grade Because we speak to professional responsibilities as a component of the course, late submissions have a negative impact on the final grade. Given the frequent communication students generally understand where they stand in the process. If performance is placing their grade at risk, the matter will be discussed and measures suggested to correct the problem.

This course has been offered to classes ranging from three to twenty students. Typically the average enrollment has been between eight and ten. Classes larger than ten cause problems with respect to having adequate discussion time for all students.

During the 2005/06 academic year a section was offered via video conference. Three students, two in Kingston and one in Saskatoon were involved. Software problems relating to audio time delays and intermittent feedback were frustrating, but the technical feasability of the approach was confirmed. Administrative details regarding student registration and fees made the technical problems seem trivial

\section{In Summary}

In general the class has been well received. In the seven years it has been offered, we have accommodated requests to participate from five different "non-students". Both instructors look forward to this course. Hopefully the students learn as much as we do.

\section{References}

[1] Koen, B.V. 1985 Definition of the engineering method. The American Society for Engineering Education, Washington, DC

[2] Florman, S.C. 1994 The existential pleasures of engineering, 2nd Edition. St. Martin's Press, New York, NY

[3] Petroski, H. 1994 Design paradigms. The Press Syndicate of the University of Cambridge, Cambridge, UK

[4] Franklin, Ursula M. 1999 The real world of technology. (CBC Massey Lectures) (Revised Edition), House of Anansi Press Inc., Toronto, ON

[5] Chiles, James R. 2001 Inviting disaster. Harper Collins Publishers, Inc., New York, NY

[6] Greene, Laura, 2005 Questioning Questions. The National Teaching and Learning Forum, February 2005 